\title{
Association of dietary patterns and degree of food processing with feelings of depression in pregnancy
}

Nayla de Lourenço Badanai 1

https://orcid.org/0000-0002-9685-9439

Daniela Cristina Candelas Zuccolotto 2

https://orcid.org/0000-0001-6472-4882

Lívia Castro Crivellenti 3

https://orcid.org/0000-0002-9038-0996

Daniela Saes Sartorelli 4

https://orcid.org/0000-0003-2028-3274

1 Graduação em Nutrição e Metabolismo. Faculdade de Medicina de Ribeirão Preto. Universidade de São Paulo.Ribeirão Preto, SP, Brasil.
2,3 Pós-Graduação em Saúde Pública.Faculdade de Medicina de Ribeirão Preto. Universidade de São Paulo. Ribeirão Preto, SP, Brasil.
4 Departamento de Medicina Social. Faculdade de Medicina de Ribeirão Preto. Universidade de São Paulo.Av. Bandeirantes, 3900. Ribeirão Preto, SP, Brasil. CEP: 14.049-
900. E-mail: daniss@fmrp.usp.br

\begin{abstract}
Objectives: to investigate the relationship of dietary patterns and degree of food processing with feelings of depression in pregnancy.

Methods: cross-sectional study conducted with 784 adult pregnant women in Ribeirão Preto, SP, between 2011 and 2012. Feelings of depression were obtained through a structured questionnaire. Two 24-hour dietary recalls were obtained (24th-39th weeks of gestation) and adjusted through the Multiple Source Method. Four dietary patterns were determined: "Brazilian traditional", "snacks", "coffee", and "healthy". Adjusted logistic regression models were used to assess the relationship ofthe tertiles of dietary patterns and energy contribution ( $\% E$ ) of foods according to the degree of industrial processing with feelings of depression (always/most of the time vs. sometimes/never).

Results: $12 \%$ of the women reported feelings of depression during the pregnancy. Women with greater adherence to "Brazilian traditional" $[O R=0.54(C I 95 \%=0.30-0.97)]$ and "healthy" patterns [0.53 (0.30-0.94)] and with higher \%E from minimally processed foods [0.51 (0.28-0.93)] presented a lower chance of feelings of depression. A higher \%E from ultra-processed foods [2.39 (1.29-4.41)] was directly associated with the outcome. No associations with the other patterns were found.

Conclusions: greater adherence to the "Brazilian traditional" and "healthy" dietary patterns was inversely associated with feelings of depression during pregnancy, possibly mediated by the degree of industrial processing of the foods.
\end{abstract}

Key words Pregnant women, Dietary habits, Industrialized foods, Depression 


\section{Introduction}

It is estimated that one in five women presents significant depressive symptoms during pregnancy 1,2 which may affect the health of future generations. Depression and other psychological disorders in the pregnant woman may expose the child to a higher risk of prematurity, low birth weight, cognitive deficits, speech disorders and depression in adult life. ${ }^{3-7}$ Accordingly, the investigation of factors related to the occurrence of this disease is of paramount importance.

Dietary patterns determined by principal component analysis reflect the food behavior of the population, this being an option for a global investigation of diet that broadly considers the variety of food consumed. 8 In a meta-analysis of observational studies, a lower risk of depression was found in adults with greater adherence to patterns rich in fruits, vegetables, whole grains, fish, olive oil and low-fat dairy products and low in foods of animal origin. ${ }^{9}$ In pregnant women, there are indications that adherence to healthy diets reduces the chance of depression, however, the number of studies is still considered insufficient. 10

A cross-sectional study conducted in Japan found an inverse association between adherence to a dietary pattern rich in vegetables, mushrooms, legumes, seaweed, potatoes, fish, seafood, misoshiro, sugar and shellfish, and to a pattern rich in rice and misoshiro, and depressive symptoms during pregnancy.11 Conversely, in a study conducted with English pregnant women no association between dietary patterns and depression was found. 12

In Brazil, a cross-sectional study conducted with 712 pregnant women found that greater adherence to a dietary pattern rich in rice, pasta, bread, beans, meat, eggs, coffee, margarine and artificial juice was associated with a higher prevalence of depressive disorder when compared to greater adherence to a pattern rich in grains, cereals, tubers, breads, cakes, cookies, fruits and vegetables. ${ }^{13}$ In a cohort study conducted with 248 pregnant women in Rio de Janeiro, it was observed that women with greater adherence to a dietary pattern rich in dairy products, natural fruits and juices, green vegetables, sweets, fish, cakes, biscuits, pasta, tubers, and tea prior to the pregnancy were at a lower risk of depression during pregnancy. 14

In a previous national study conducted with 784 adult pregnant women, four dietary patterns were identified, two of which were characterized by high consumption of minimally processed foods and low consumption of ultra-processed products. ${ }^{15}$ The socalled "Brazilian traditional" pattern was directly associated with the consumption of rice, beans, meat and vegetables and inversely associated with the consumption of snacks, pizzas, sandwiches, cheese and cream cheese and the "healthy" pattern was directly related to the consumption of vegetables, fruits and natural juice and inversely related to the consumption of artificial juices and sodas. The other dietary patterns were composed of both minimally processed and ultra-processed foods: the "snack" pattern (directly associated with the consumption of bread, butter, margarine, cold cuts, milk, yogurts, cheese, cream cheese, chocolate and sweets) and the "coffee" pattern"(directly associated with the consumption of coffee, sugar, butter and margarine). 15

Evidence suggests that the consumption of fresh and/or minimally processed foods may play a protective role in the risk of perinatal depression. 16 Conversely, a high consumption of ultra-processed products has been associated with a higher occurrence of depression in pregnancy. 17 Accordingly, the consumption of minimally processed foods can be considered a marker of healthy eating, allowing the monitoring of diet quality according to recommendations of the food guide. 18

Considering the undesirable effects of depression during pregnancy on the health of the motherchild binomial, it is essential, in the context of public health, to evaluate the factors associated with this disease. Therefore, the aim of the present study was to investigate the relationship between adherence to dietary patterns and feelings of depression or sadness during pregnancy. Additionally, the relationship between food consumption according to the degree of industrial processing and the investigated outcome was evaluated. The hypothesis of the present study was that greater adherence to dietary patterns characterized by high consumption of minimally processed foods and low consumption of ultraprocessed products would present an inverse association with feelings of depression or sadness in pregnancy.

\section{Methods}

In the present study, data from a cross-sectional study conducted with 784 adult pregnant women attending prenatal care in Primary Health Units of Ribeirão Preto, SP, between 2011 and 2012, were used. Theaim of this original study was to investigate the relationship between maternal diet and gestational diabetes mellitus (GDM), as described in 
detail by Barbieiri et al. 19

The inclusion criteria for the study were: age: $\geq 20$ years, gestational age $\geq 24$ and pre-gestational body mass index $(B M I) \geq 20 \mathrm{~kg} / \mathrm{m}^{2}$. Pregnant women with pre-gestational BMI $<20 \mathrm{~kg} / \mathrm{m}^{2}$ were excluded in order to select women with a higher chance of GDM. Women who reported having diabetes or diseases that could alter their food intake were excluded. To calculate the sample size, the prevalence of $20 \%$ of GDM was considered, this being the primary outcome of the study. Among the women assisted in the Brazilian National Health System, 20 considering a margin of error of $5 \%$, a sample of at least 512 pregnant women was required. Of the 1,446 pregnant women contacted, 639 were excluded ( 288 due to being $<20$ years of age, $83 \mathrm{BMI}$ $<20 \mathrm{~kg} / \mathrm{m}^{2}, 1$ previous diabetes, 1 using corticosteroids, and 20 that did not complete the examination), 19 refused to participate in the study and 4 had incomplete data, totaling a sample of 784 pregnant women.

The women were interviewed at the time of the oral glucose tolerance test, between the $24^{\text {th }}$ and $39^{\text {th }}$ gestational weeks, by trained nutritionists, at which time they underwent an anthropometric evaluation and answered a structured questionnaire covering socioeconomic and lifestyle data.

The present study was approved by the Research Ethics Committee of the School Health Center of the Ribeirão Preto Medical School, University of São Paulo, (CAAE: 70689917.9.0000.5414).

During the interview, the pregnant women were asked about feelings of depression or sadness in the pregnancy using the question:"During the pregnancy did you have depression or sadness?", Having as response options:"Always", "most of the time", "sometimes" or "never".In the present study the answers were grouped into:"always" or "most of the time" (yes) "sometimes" or "never" (no). This methodology was validated and considered appropriate in screening for individuals at risk of disease, 21,22 with a previous study conducted among pregnant women showing a sensitivity of $91 \%$ and specificity of $52 \%$ regarding the diagnosis of the disease through Beck's Depression Inventory. ${ }^{23}$ Although not a diagnosis of depression, it is considered suitable for use in epidemiological studies. ${ }^{22}$

The food intake was assessed by means of two 24-hour dietary recalls (24HRs) using the multiplepass methodology in three stages. 24 The first $24 \mathrm{HR}$ was collected in person and the second through telephone contact with at least seven days apart, regardless of the day of the week or season. To estimate usual food intake, the Multiple Source Method
(MSM) was used, this being a statistical modeling technique that uses the usual consumption distribution estimated by combining probability and quantity consumed. 25

The dietary patterns were determined through principal component analysis using Varimax rotation, as described in detail by Zuccolotto et al. 15 Four dietary patterns were identified:"Brazilian traditional", "healthy", "snacks" and "coffee", the first two being characterized by a high consumption of minimally processed foods and low consumption of ultra-processed products, and the other dietary patterns composed of both minimally processed and ultra-processed foods. 15

The classification of foods according to the degree of industrial processing (fresh or minimally processed, processed and ultra-processed) was defined according to the recommendations of the Food Guide for the Brazilian Population.18 Minimally processed foods are foods that have been processed, but without substances added, or elements removed (i.e. coffee, natural fruit juice and pasteurized whole milk). Processed foods are foods manufactured industrially with the addition of salt, sugar, oil and fats (i.e. canned foods, cheese). Ultraprocessed products are produced by the food industry using substances extracted from food or obtained by chemical synthesis (i.e. soft drinks, sugar, sugary drinks, crackers, cookies, instant noodles, flavored yoghurts). 18 Culinary preparations were classified according to the main component of the recipe.

The age (years), education of the pregnant woman and head of the household (in years of schooling), gestational week, marital status (married/with partner, single, separated or widowed), self-declaration of skin color, possession of items, ${ }^{26}$ practice of physical activity (minutes per week of walking or exercise), smoking history (never smoked, former smoker or current smoker), alcohol consumption during pregnancy (yes or no) and sleep time were obtained through structured questionnaires.

The gestational week at the time of the interview was estimated based on the date of the last menstruation recorded on the pregnant woman's card, later corrected from the ultrasound data recorded in the medical record.

The amount of sleep was categorized as adequate (7 | -9 hours/day), insufficient ( $<7$ hours/day) and excessive ( $\geq 9$ hours/day).27 For the classification of the economic stratum, the Economica Brasil Classification Criterion (CCEB - Portuguese acronym) was used, which defines the economic 
strata from A ( $>$ level) to $\mathrm{E}(<$ level) based on the interviewee's responses regarding ownership of property, and education level of the head of the household. 26

During the interview, women underwent an anthropometric evaluation, with weight (in kilos) and height (in meters) obtained using a digital scale (TANITA model HS302) and a portable stadiometer (SANNY model ES2040), respectively, adopting the protocol proposed by the Ministry of Health. 28 The pre-pregnancy weight (in kilos) of the women was obtained based on data recorded on the pregnant woman's obstetric monitoring card. The pre-gestational body mass index (BMI) was obtained through the ratio of weight $(\mathrm{kg})$ by height $(\mathrm{m})$ squared.

To investigate differences between the maternal characteristics according to feelings of depression or sadness, Student's t-test, the Mann Whitney test or the chi-square test were used.

The pregnant women's scores regarding adherence to each of the eating patterns were categorized into tertiles. Women classified in the first tertile were considered to have low adherence and in the third tertile, high adherence. The energy contribution $(\% \mathrm{E})$ of the foods according to the degree of industrial processing (minimally processed, processed and ultra-processed) was also expressed in tertiles. For the description of self-report of feelings of depression or sadness of the pregnant women according to adherence to dietary patterns and food consumption the chi-square test was used.

Adjusted logistic regression models were employed and odds ratio (OR) values and 95\% confidence intervals (CI95\%) were estimated to assess the relationship between adherence to dietary patterns and the $\% \mathrm{E}$ of the foods according to the degree of industrial processing, and feelings of depression or sadness (yes, no) during the pregnancy. The adjustment variables considered were: age (years), education of the pregnant woman (years of schooling), marital status (single, married/with partner, separated/widowed), smoking (never smoked, former smoker, smoker), alcohol consumption (yes, no), practice of physical activity (minutes per week of walking or exercise), pre-gestational BMI classification $\left(\mathrm{kg} / \mathrm{m}^{2}\right)$, amount of sleep per day $(<7,7 \mid-9, \geq 9$ hours per day), gestational week at the time of the interview (weeks) and total dietary energy (kcal). These variables were selected based on the theoretical framework of the influence on food consumption, as well as on the occurrence of depression. All the variables were simultaneously included in the models. The $p$ value $<0.05$ was adopted as significant and the analyses were performed using the SPSS version 21 software.

\section{Results}

Of the 784 women interviewed, 94 (12\%) reported feeling depressed or sadness during pregnancy, with these women presenting a mean (SD) age of 29 (6) years and 9 (3) years of schooling, the majority of them were married/with partner $(69.1 \%)$, white $(47.9 \%)$ and belonged to economic stratum C $(64.9 \%)$ (Table 1). The women were interviewed on average during the $28^{\text {th }}$ (3) gestational week, ranging from the $24^{\text {th }}$ to $39^{\text {th }}$ week.

Pregnant women who reported feeling depression or sadness "always" or "most of the time"presented a higher mean age, with a higher proportion reportingan insufficient amount of sleep ( $<7$ hours/day), a higher percentage of smokers, and more reporting being divorced or widowed, when compared to those who reported feeling depressed or sad "sometimes" or "never" (Table 1). There was no difference regarding education level, pre-gestational BMI, gestational week at the time of the interview, economic status, self-report of skin color, alcohol consumption and practice of physical activity according to feelings of depression or sadness (Table $1)$.

It was found that there was no difference between self-reported feelings of depression or sadness during the pregnancy and adherence to the dietary patterns. There was a higher frequency of feelings of depression among the women who reported higher $\% \mathrm{E}$ from ultra-processed foods (Table 2).

In the adjusted logistic regression models, women with greater adherence to the "Brazilian traditional" $[\mathrm{OR}=0.54(\mathrm{CI} 95 \%=0.30-0.97)]$ and "healthy" $[\mathrm{OR}=0.53(\mathrm{CI} 95 \%=0.30-0.94)]$ dietary patterns presented a lower chance of feeling depressed or sad when compared to those with lower adherence to these eating patterns, regardless of confounding factors (Table 3). There was no association between the "snack" and "coffee" patterns and feelings of depression or sadness during pregnancy.

After adjustments for confounding factors, it was found that the pregnant women categorized in the third tertile of $\% \mathrm{E}$ from minimally processed foods had a lower chance of feeling depressed or sad [OR= $0.51(\mathrm{CI} 95 \%=0.28-0.93)]$ when compared to the pregnant women in the first tertile. In contrast, the pregnant women ranked in the third tertile of $\% \mathrm{E}$ fromultra-processed foods had a higher chance of feeling depressed or $\mathrm{sad}[\mathrm{OR}=2.39(\mathrm{CI} 95 \%=1.29$ 4.41)], compared to those classified in the first tertile (Table 4). 
Characteristics of pregnant women according to the self-report of feelings of depression or sadness. Ribeirão Preto, SP. 2011-2012 $(n=784)$.

\begin{tabular}{|c|c|c|c|c|}
\hline \multirow[t]{2}{*}{ Maternal characteristics } & \multicolumn{3}{|c|}{ Self report of feelings of depression or sadness } & \multirow[t]{2}{*}{$p^{*}$} \\
\hline & All $(n=784)$ & Yes $(n=94)$ & No $(n=690)$ & \\
\hline \multicolumn{5}{|c|}{ Mean (SD) } \\
\hline Age (years) & $28(5)$ & $29(6)$ & $27(5)$ & 0.002 \\
\hline Education (years of study) & $9(3)$ & $9(3)$ & $9(3)$ & 0.470 \\
\hline Pre-gestational BMI (kg/m²) & $26(5)$ & $26(5)$ & $26(5)$ & 0.290 \\
\hline Gestational week at interview & $28(3)$ & $28(3)$ & $28(3)$ & 0.590 \\
\hline \multicolumn{5}{|c|}{$\mathrm{n}(\%)$} \\
\hline \multicolumn{5}{|l|}{ Marital status } \\
\hline Married/with partner & $615(78.4)$ & $65(69.1)$ & $550(79.7)$ & 0.001 \\
\hline Single & $143(18.2)$ & $20(21.3)$ & $123(17.8)$ & \\
\hline Separated/widowed & $26(3.3)$ & $9(9.6)$ & $17(2.5)$ & \\
\hline \multicolumn{5}{|l|}{ Economic stratum } \\
\hline$A+B$ & $154(19.6)$ & $20(21.3)$ & $134(19.4)$ & 0.880 \\
\hline c & $526(67.1)$ & $61(64.9)$ & $465(67.4)$ & \\
\hline$D+E$ & $104(13.3)$ & $13(13.8)$ & $91(13.2)$ & \\
\hline \multicolumn{5}{|l|}{ Self-report of skin color } \\
\hline White & $349(44.5)$ & $45(47.9)$ & $304(44.1)$ & 0.230 \\
\hline Non-white & $435(55.5)$ & $49(52.1)$ & $386(55.9)$ & \\
\hline \multicolumn{5}{|l|}{ Amount of sleep (hours/day) } \\
\hline$<7$ & $125(15.9)$ & $25(26.6)$ & $100(14.5)$ & 0.003 \\
\hline $71-9$ & $326(41.6)$ & $41(43.6)$ & $285(41.3)$ & \\
\hline$\geq 9$ & $333(42.5)$ & $28(29.8)$ & $305(44.2)$ & \\
\hline Alcohol consumption during pregnancy & $197(25.0)$ & $29(31.0)$ & $168(24.0)$ & 0.110 \\
\hline \multicolumn{5}{|l|}{ Smoking status } \\
\hline Never smoked & $623(79.5)$ & $68(72.3)$ & $555(80.4)$ & 0.005 \\
\hline Currently smokes & $71(9.1)$ & $17(18.1)$ & $54(7.8)$ & \\
\hline \multirow[b]{3}{*}{ Dhucical otivitu (minutoc } & $90(11.5)$ & $9(9.6)$ & $81(11.8)$ & \\
\hline & & Median $\left(P_{25}, P_{75}\right)$ & & \\
\hline & $40(0.136)$ & $60(0.150)$ & $40(0.120)$ & 0.180 \\
\hline
\end{tabular}

\footnotetext{
* $p$ value according to Student's $t$-test for continuous variables with normal distribution, Mann-Whitney $U$ test for
} continuous variables without normal distribution or Chi-square test for categorical variables. 
Self-reported frequency of feelings of depression or sadness during pregnancy according to adherence to dietary patterns, and food consumption according to the degree of industrial processing. Ribeirão Preto, SP.2011-2012 $(n=784)$.

\begin{tabular}{|c|c|c|c|c|c|c|c|}
\hline & \multicolumn{6}{|c|}{ Self report of feelings of depression or sadness } & \multirow[t]{3}{*}{$p^{*}$} \\
\hline & \multicolumn{2}{|c|}{ All $(n=784)$} & \multicolumn{2}{|c|}{ Yes $(n=94)$} & \multicolumn{2}{|c|}{ No $(n=690)$} & \\
\hline & $\mathrm{n}$ & $\%$ & $\mathrm{n}$ & $\%$ & $\mathrm{n}$ & $\%$ & \\
\hline \multicolumn{8}{|c|}{ Eating patterns (Tertiles) } \\
\hline \multicolumn{8}{|c|}{ Traditional Brazilian } \\
\hline $1^{\text {st }}$ & 260 & 33.2 & 38 & 40.4 & 222 & 32.2 & 0.07 \\
\hline $2^{\text {nd }}$ & 262 & 33.4 & 34 & 36.2 & 228 & 33.0 & \\
\hline 3 rd & 262 & 33.4 & 22 & 23.4 & 240 & 34.8 & \\
\hline \multicolumn{8}{|l|}{ Snacks } \\
\hline 1 st & 260 & 33.2 & 28 & 29.8 & 232 & 33.6 & 0.13 \\
\hline $2^{\text {nd }}$ & 262 & 33.4 & 40 & 42.6 & 222 & 32.2 & \\
\hline $3 r d$ & 262 & 33.4 & 26 & 27.6 & 236 & 34.2 & \\
\hline \multicolumn{8}{|l|}{ Coffee } \\
\hline 1 st & 261 & 33.3 & 27 & 28.8 & 234 & 33.9 & 0.55 \\
\hline $2^{\text {nd }}$ & 262 & 33.4 & 32 & 34.0 & 230 & 33.3 & \\
\hline 3 rd & 261 & 33.3 & 35 & 37.2 & 226 & 32.8 & \\
\hline \multicolumn{8}{|l|}{ Healthy } \\
\hline 1 st & 260 & 33.2 & 38 & 40.4 & 223 & 32.3 & 0.22 \\
\hline $2^{\text {nd }}$ & 262 & 33.4 & 31 & 33.0 & 231 & 33.5 & \\
\hline 3 rd & 262 & 33.4 & 25 & 26.6 & 236 & 34.2 & \\
\hline \multicolumn{8}{|c|}{ Food consumption by degree of } \\
\hline \multicolumn{8}{|c|}{ Minimally processed } \\
\hline 1 st & 261 & 33.3 & 38 & 40.0 & 223 & 32.4 & 0.12 \\
\hline $2^{\text {nd }}$ & 261 & 33.3 & 33 & 35.1 & 228 & 33.0 & \\
\hline $3 r d$ & 262 & 33.4 & 23 & 24.5 & 239 & 34.7 & \\
\hline \multicolumn{8}{|l|}{ Processed } \\
\hline 1 st & 261 & 33.3 & 29 & 30.9 & 232 & 33.6 & 0.86 \\
\hline $2^{\text {nd }}$ & 261 & 33.3 & 32 & 34.0 & 229 & 33.2 & \\
\hline $3 \mathrm{rd}$ & 262 & 33.4 & 33 & 35.1 & 229 & 33.2 & \\
\hline \multicolumn{8}{|c|}{ Ultra Processed } \\
\hline 1 st & 261 & 33.3 & 21 & 22.3 & 240 & 34.8 & 0.04 \\
\hline $2^{\text {nd }}$ & 261 & 33.3 & 33 & 35.1 & 228 & 33.0 & \\
\hline 3 rd & 262 & 33.4 & 40 & 42.6 & 222 & 32.2 & \\
\hline
\end{tabular}

*Chi-square test. 
Relationship between adherence to dietary patterns and self-reported feelings of depression or sadness during pregnancy. Ribeirão Preto, SP. 2011-2012 ( $n=784)$ *

\begin{tabular}{|c|c|c|c|c|}
\hline Eating patterns & 1st Tertile & 2nd Tertile & 3rd Tertile & $p$ \\
\hline \multicolumn{5}{|c|}{ "Brazilian Traditional"pattern } \\
\hline Crude model & 1.00 & $0.87(0.53,1.43)$ & $0.54(0.31,0.93)$ & 0.03 \\
\hline Adjusted model** & 1.00 & $0.92(0.55,1.54)$ & $0.54(0.30,0.97)$ & 0.04 \\
\hline \multicolumn{5}{|l|}{ "Snacks" pattern } \\
\hline Crude model & 1.00 & $1.49(0.89,2.50)$ & $0.91(0.52,1.60)$ & 0.76 \\
\hline Adjusted model** & 1.00 & $1.54(0.89,2.66)$ & $0.91(0.49,1.67)$ & 0.76 \\
\hline \multicolumn{5}{|l|}{ "Coffee" pattern } \\
\hline Crude model & 1.00 & $1.21(0.70,2.08)$ & $1.34(0.79,2.29)$ & 0.28 \\
\hline Adjusted model** & 1.00 & $1.28(0.64,1.98)$ & $1.13(0.65,1.97)$ & 0.67 \\
\hline \multicolumn{5}{|l|}{ "Healthy" pattern } \\
\hline Crude model & 1.00 & $0.79(0.47,1.31)$ & $0.62(0.36,1.06)$ & 0.08 \\
\hline Adjusted model** & 1.00 & $0.73(0.43,1.23)$ & $0.53(0.30,0.94)$ & 0.03 \\
\hline
\end{tabular}

* Odds ratio (OR) and $95 \%$ confidence interval (CI95\%) obtained through logistic regression models; ** Models adjusted for: age (years), education (years of schooling), marital status (single, married/with partner/widowed), smoking (never smoked, former smoker, smoker), alcohol consumption (yes/no), physical activity (minutes per week of walking or exercise), pre-gestational BMI ( $\left.\mathrm{kg} / \mathrm{m}^{2}\right)$, amount of sleep ( $<7 ; 7 \mathrm{l}-9 ; \geq 9$ hours per day), gestational week at the time of interview (weeks) and total dietary energy (kcal).

\section{Table 4}

Relationship between the consumption of minimally processed, processed and ultra-processed foods and the selfreport of feelings of depression or sadness during pregnancy. Ribeirão Preto, SP. 2011-2012 $(n=784)$.*

\begin{tabular}{|c|c|c|c|c|}
\hline $\begin{array}{l}\text { Food consumption } \\
(\% \mathrm{E})\end{array}$ & 1st Tertile & $2^{\text {nd }}$ Tertile & $3^{\text {rd }}$ Tertile & $p$ \\
\hline \multicolumn{5}{|l|}{ Minimally processed } \\
\hline Crude model & 1.00 & $0.85(0.51-1.40)$ & $0.57(0.33-0.98)$ & 0.04 \\
\hline Adjusted model** & 1.00 & $0.87(0.51-1.47)$ & $0.51(0.28-0.93)$ & 0.03 \\
\hline \multicolumn{5}{|l|}{ Processed } \\
\hline Crude model & 1.00 & $1.12(0.66-1.91)$ & $1.15(0.68-1.96)$ & 0.60 \\
\hline Adjusted model** & 1.00 & $1.06(0.61-1.83)$ & $1.15(0.66-1.98)$ & 0.62 \\
\hline \multicolumn{5}{|l|}{ Ultra-processed } \\
\hline Crude model & 1.00 & $1.65(0.93-2.94)$ & $2.06(1.18-3.60)$ & 0.01 \\
\hline Adjusted model** & 1.00 & $1.87(1.01-3.43)$ & $2.39(1.29-4.41)$ & 0.01 \\
\hline
\end{tabular}

*Odds ratio (OR) and $95 \%$ confidence interval (CI95\%) obtained through logistic regression models; ** Models adjusted for: age (years), education (years of schooling), marital status (single, married/with partner/widowed), smoking (never smoked, former smoker, smoker), alcohol consumption (yes/no), physical activity (minutes per week of walking or exercise), pre-gestational BMI $\left(\mathrm{kg} / \mathrm{m}^{2}\right)$, amount of sleep $(<7 ; 7 \mathrm{l}-9$; $\geq 9$ hours per day), gestational week at the time of interview (weeks) and total dietary energy (kcal). TCV = Total caloric value. 


\section{Discussion}

In the present study, it was observed that women with higher adherence to the "Brazilian traditional" and "healthy" dietary patterns had a lower chance of feeling depressed or sad "always" or "most of the time" during pregnancy, regardless of confounding factors. These patterns were characterized by high consumption of minimally processed foods and low consumption of ultra-processed products. An inverse relationship between the $\% \mathrm{E}$ from minimally processed foods and feelings of depression during the pregnancy was verified, as was a direct relationship between the $\% \mathrm{E}$ from ultra-processed foods and this outcome.

The findings of the present study agree with international evidence suggesting an inverse association between adherence to dietary patterns that are mainly composed of minimally processed foods and depression in adults 9 and pregnant women.10,11 However, due to distinct characteristics of the dietary culture verified among the population studied, the comparison of the findings is limited, as the dietary patterns determined through principal component analysis identify the eating behavior of the study population. 8

Comparing the results observed with Brazilian studies with culturally similar populations also presents limitations. The heterogeneity in the composition and nomenclature of the dietary patterns and the low number of studies make this task difficult.

The only national investigation identified that assessed the relationship between dietary patterns in pregnancy and depression was a cross-sectional study conducted by Paskulin et al.13 with 712 pregnant women in southern Brazil. Three dietary patterns were identified, called "restricted", "varied" and "common Brazilian". The authors observed a higher prevalence of depressive disorder among pregnant women with lower fruit consumption and higher consumption of sweets and sugars, corroborating the results of the present study.

Because the findings of the present study suggested a relationship between the degree of industrial food processing and the outcome investigated, complementary analyses were conducted to test this hypothesis. There was an inverse relationship between $\% \mathrm{E}$ from minimally processed foods and feelings of depression or sadness during the pregnancy, as well as a direct relationship between $\% \mathrm{E}$ from ultra-processed foods and these feelings.

Evidence suggests that a high \%E from ultraprocessed foods is associated with increased gesta- tional weight gain and neonatal body fat, which may cause several short- and long-term pregnancy and fetal problems, including problems related to mental health. ${ }^{29}$ A descriptive study conducted with lowincome, pregnant American women found that women that reported consuming fast foods $\geq 3$ times a week were more likely to experience depression and stress during the pregnancy. ${ }^{17}$ In contrast, natural and minimally processed foods are rich in micronutrients, such as folate, vitamin D, iron, selenium and zinc, which have been identified as possible protectors from depression during pregnancy. 16 Furthermore, there is evidence that adherence to dietary patterns rich in fruits, vegetables, fish and whole grains, and low consumption of processed meats, refined cereals and sweets is protective for depression in adults. 9

One of the limitations of the present study is the cross-sectional design, which makes it impossible to assess the temporal relationship between the feelings of depression or sadness in pregnancy and the dietary patterns. There is a possibility that women who are at risk for depression may be less motivated to eat properly, therefore adhering to unhealthy eating patterns. Another limitation is the self-report of feelings of sadness and depression, theoutcome employed in the present study, which is not a diagnosis of depression but a screening for individuals at risk of developing the disease. Although the scale used was previously validated for pregnant women, 17,18 it was not evaluated in Brazil, which may partially explain the low prevalence of depression verified among the study participants. However, rapid screening methods, as used in the present study, are considered efficient for identifying individuals at risk of developing depression, with acceptable sensitivity and specificity regarding the diagnosis of the disease, and can be applied by any primary care professional. ${ }^{19,20,21}$ It should be considered that the frequency of feelings of depression or sadness may not have been captured among the women with early gestational age, since the data collection occurred between the $24^{\text {th }}$ and $39^{\text {th }}$ gestational weeks. Only pregnant women with BMI $\geq 20$ $\mathrm{kg} / \mathrm{m}^{2}$ were included and extrapolation of findings to women with lower BMI may be misleading. Data on weight gain during the first trimester of pregnancy were not collected, making it impossible to estimate the relevance of weight gain, therefore the models were adjusted by the pre-gestational BMI.

Among the strengths of the study, it should be highlighted that the present study was unprecedented in assessing the relationship between $\% \mathrm{E}$ of foods according to the degree of industrial processing and 
feelings of depression in pregnancy. It was possible to identify an inverse relationship between adherence to the dietary patterns characterized by high consumption of minimally processed foods and low consumption of ultra-processed products with feelings of sadness and depression during pregnancy.

Higher adherence to the "Brazilian traditional" and "healthy" dietary patterns, characterized by high consumption of minimally processed foods and low consumption of ultra-processed products, was inversely associated with feelings of depression or sadness during pregnancy. Data suggest an inverse relationship between $\% \mathrm{E}$ from minimally processed foods and feelings of depression, as well as a direct

\section{References}

1. Melville JL, Gavin A, Guo Y, Fan MY, Katon WJ. Depressive disorders during pregnancy: prevalence and risk factors in a large urban sample. ObstetGynecol. 2010; 116 (5): 1064-70.

2. Ryan J, Mansell T, Fransquet P, Saffery R. Does maternal mental well-being in pregnancy impact the early human epigenome? Epigenomics. 2017; 9 (3): 313-32.

3. Staneva A, Bogossian F, Pritchard M, Wittkowski A. The effects of maternal depression, anxiety, and perceived stress during pregnancy on preterm birth: a systematic review. WomenBirth. 2015; 28 (3): 179-93.

4. Eastwood J, Ogbo FA, Hendry A, Noble J, Page A, Early Years Research Group (EYRG). The Impact of Antenatal Depression on Perinatal Outcomes in Australian Women. PLoSOne. 2017; 12 (1): e0169907.

5. Weikum WM, Oberlander TF, Hensch TK, Werker JF. Prenatal exposure to antidepressants and depressed maternal mood alter trajectory of infant speech perception. ProcNatlAcadSci USA. 2012; 109 (Suppl. 2): 17221-7.

6. Pawlby S, Hay DF, Sharp D, Waters CS, O'Keane V. Antenatal depression predicts depression in adolescent offspring: prospective longitudinal community-based study. J AffectDisord. 2009; 113 (3): 236-43.

7. Slykerman RF, Thompson J, Waldie K, Murphy R, Wall C, Mitchell EA. Maternal stress during pregnancy is associated with moderate to severe depression in 11-year-old children. Acta Paediatr. 2015; 104 (1): 68-74.

8. Hu, FB. Dietary pattern analysis: a new direction in nutritional epidemiology. CurrOpinLipidol. 2002; 13 (1): 3-9.

9. Li Y, Lv MR, Wei YJ,Sun L,Zhang JX, Zhang HG, Li B. Dietary patterns and depression risk: A meta-analysis. Psychiatry Res. 2017; 253: 373-382.

10. Baskin R, Hill B,Jacka FN,O'Neil A,Skouteris H. The association between diet quality and mental health during the perinatal period, a systematic review. Appetite. 2015; 91: 41-7.

11. Miyake Y, Tanaka K,Okubo H,Sasaki S,Furukawa $\mathrm{S}$,Arakawa M. Dietary patterns and depressive symptoms during pregnancy in Japan: Baseline data from the Kyushu relationship between $\% \mathrm{E}$ of ultra-processed foods and this outcome. The other eating patterns were not associated with feelings of depression or sadness among pregnant women.

\section{Authors' contribution}

NLB and DSS were responsible for the study design, data analysis, interpretation and writing of the manuscript. LCC and DCCZ contributed to the data collection, analysis and interpretation, and reviewed the manuscript. All the authors approved the final version of the manuscript.
Okinawa Maternal and Child Health Study. J AffectDisord. 2018; 225: 552-8.

12. Molyneaux E,Poston L,Khondoker M,Howard LM. Obesity, antenatal depression, diet and gestational weight gain in a population cohort study. ArchWomensMent Health. 2016; 19: 899-907.

13. Paskulin JTA,Drehmer M,Olinto MT,Hoffmann JF,Pinheiro AP,Schmidt MI. Association between dietary patterns and mental disorders in pregnant women in Southern Brazil. RevBras Psiquiatr. 2017; 39 (3): 208-15.

14. Vilela AA, Farias DR, Eshriqui I, Vaz Jdos S, Franco-Sena AB, Castro MB, Olinto MTA, Machado SP, Silva AAM, Kac G. Prepregnancy healthy dietary pattern is inversely associated with depressive symptoms among pregnant Brazilian women. J Nutr. 2014; 144 (10): 1612-8.

15. Zuccolotto DCC, Crivellenti LC, Franco LJ, Sartorelli DS. Padrões alimentares de gestantes, excesso de peso materno e diabetes gestacional. RevSaúde Pública. 2019; in press.

16. Sparling TM, Nesbitt RC, Henschke N, Gabrysch S. Nutrients and perinatal depression: a systematic review. J Nutr Sci. 2017; 6: e61.

17. Fowles ER, Timmerman GM, Bryant M, Kim S. Eating at fast-food restaurants and dietary quality in low-income pregnant women. West J Nurs Res. 2011; 33(5): 630-51.

18. Brasil. Ministério da Saúde. Secretaria de Atenção à Saúde, Departamento de Atenção Básica. Guia alimentar para população brasileira. 2 ed. Brasília (DF); 2014. [acesso em 31 ago 2018]. Disponível em: http://bvsms. saude.gov.br/bvs/ publicacoes/guia_alimentar_ populacao_brasileira_2ed.pdf.

19. Barbieiri P, Nunes JC, Torres AG, Nishimura RY, Zuccolotto DC, Crivellenti LC, Franco LJ,Sartorelli DS.Indices of dietary fat quality during midpregnancy is associated with gestational diabetes. Nutrition. 2015;32 (6): 656-61.

20. Trujillo J, Vigo A, Reichelt A, Duncan BB, Schmidt MI. Fasting plasma glucose to avoid a full OGTT in the diagnosis of gestational diabetes. Diabetes Res Clin Pract. 2014; 105 (3): 322-6. 
21. Mahoney J, Drinka TJ, Abler R, Gunter-Hunt G, Matthews C, Gravenstein S, Carnes M. Screening for depression: single question versus GDS. J Am Geriatr Soc. 1994; 42 (9): 1006-8

22. Konstantakopoulos G, Sofianopoulou E, Touloumi G, Ploumpidis D. Ultra-short questionnaires for the detection of depression and anxiety. Psychiatriki. 2013; 24 (4): 28897.

23. Jesse DE, Graham M. Are you often sad and depressed? Brief measures to identify women at risk for depression in pregnancy. MCN Am J MaternChildNurs. 2005; 30 (1): 40 5 .

24. Jonhson RK, Soultanakis RP, Matthews, DE. Literacy and body fatness are associated with underreporting of energy intake in US low-income using the multiple-pass 24-hour recall: A doubly labeled water study. J Am Diet Assoc. 1998; 98 (10): 1136-40

25. Harttig U, Haubrock J, Knuppel S, Boeing H, EFCOVAL Consortium. The MSM program: web-based statistics package for estimating usual dietary intake using the Multiple Source Method. Eur J Clin Nutr 2011; 65(Suppl. 1):S87-91.

26. ABEP (Associação Brasileira de Empresa de Pesquisa). Dados com base no levantamento socioeconômico 2012 IBOPE. São Paulo; ABEP; 2012 [acesso em 31 ago 2018]. Disponível em: http://www.abep.org.
27. Watson NF, Badr MS, Belenky G, Bliwise DL, Buxton OM, Buysse D, Dinges DF,Gangwisch J,Grandner MA,Kushida C,Malhotra RK,Martin JL,Patel SR,Quan SF,Tasali E.Recommended Amount of Sleep for a Healthy Adult: A Joint Consensus Statement of the American Academy of Sleep Medicine and Sleep Research Society. Sleep. 2015; 38 (6): $843-4$

28. Brasil. Ministério da Saúde. Secretaria de Atenção à Saúde. Departamento de Atenção Básica. Orientações para a coleta e análise de dados antropométricos em serviços de saúde: Norma Técnica do Sistema de Vigilância Alimentar e Nutricional - SISVAN / Ministério da Saúde, Secretaria de Atenção à Saúde, Departamento de Atenção Básica. Brasília; 2011.

29. Rohatgi KW, Tinius RA, Cade WT, SteeleEM, Cahill AG, Parra DC. Relationships between consumption of ultraprocessed foods, gestational weight gain and neonatal outcomes in a sample of US pregnant women. PeerJ. 2017; 5: e4091.

Received on February 4, 2019

Final version presented on May 2, 2019

Approved on May 30, 2019 